\title{
Mobile Communication Evolution
}

\author{
Kuboye Bamidele Moses \\ Department of Computer Science, Federal University of Technology, PMB 704, Akure, Nigeria. \\ kubonline@yahoo.co.uk, bmkuboye@futa.edu.ng
}

\begin{abstract}
Presently, there is a wide establishment of mobile computing across the globe and the number of subscribers worldwide including Nigeria is on the increase every day. It started with mobile voice communication and has gradually been extended to the capability of sending and receiving data across the cellular networks. Also, the coming of this technology has changed the face of business all over the world and will soon dominate all strata of the society. Therefore, this paper is looking at the past, present and the future of this technology, the areas of applications and vectors of mobility that are likely to shape the future of the technology. The reviews of the mobile computing technology from the First generation (1G) to fourth (4G) are presented. The relationships of the generations were presented. The issues relating to the emergence of new technology are also reviewed. The interworking of the technologies and how they helped in promoting the mobile technologies were also reviewed. The deployments issues from First generation (1G) to 3G and later to $4 \mathrm{G}$ are presented. The paper has reviewed how each of the technology came to being and thus served as an eye opener to those people that are not acquainted with these technologies.
\end{abstract}

Index Terms - Mobile computing, Mobile Communication, GSM, GPRS, EDGE, UMTS.

\section{INTRODUCTION}

Mobile communication is the use of mobile handsets to connect to the cell site using a radio channel to communicate with other subscribers on the mobile network stations. Each mobile uses a separate, temporary radio channel to talk to the cell site. Traditional mobile service was structured similar to television broadcasting where one very powerful transmitter located at the highest spot in an area would broadcast in a radius of up to fifty kilometers while the cellular concept structured the mobile telephone network in a different way [1]. Instead of using one powerful transmitter, many lowpower transmitters were used throughout the coverage area, which determines the size of the cells.

The cellular concept employs variable low-power level transceivers, which determine the cell size, to connect with the mobile handsets for communication. The cellular equipment can communicate with the mobiles as long as they are within range. The low-power level transceiver is called channels, which are located at the Base Transceiver station (BTS). Since radio energy dissipates over distance, the mobiles must be within the operating range of the base station for communication [2].

In the early 1980s, most mobile telephone systems were analog rather than digital. One challenge facing analog systems was the inability to handle the growing capacity needs in a cost-efficient manner because analog transceiver can only handle one call at a time. As a result, digital technology was welcomed. The advantages of digital systems over analog systems include ease of signaling, lower levels of interference, integration of transmission and switching, and increased ability to meet capacity demands [1].

The need for mobile computing came because of the need to access information anywhere, anytime. The increasing need of mobile telephone and devices for data communication drives the need for a fast, reliable and available infrastructure. Mobile communications are now offering a lot of services ranging from mobile Internet, multimedia, e-mails and so on. Mobile terminals are now becoming complex embedded systems, with stringent real time requirements for signaling and voice processing [2]. In the quest to meet the demand of mobile computing, wireless communication has witness a lot of transformation from one generation to the other and a lot of changes are still going to take place in this field in the nearest future. In this paper we are going to look at the generations of wireless communication that we have till date, the mobility path taken and the expected generation features.

The rest of the paper is organized as follows. Section II describes analogue Systems and their relationships while section III gives details about $2 \mathrm{G}$ and $2.5 \mathrm{G}$ Networks. Afterwards, section IV gives the description of 3G Wireless Systems and section V explains 3.5G systems. Section VI and VII analyzes Fourth-Generation Wireless Systems (4G) and technological advancement that resulted to $4 \mathrm{G}$ while section VIII concludes the paper.

\section{ANALOGUE SYSTEMS}

Analog radio systems were the first generation of wireless or mobile communication system. They were developed between the 1970s to early 1980s and they were meant for voice transfer [3]. A group of people from the equipment manufacturers, government and telecommunication industry worked together as a committee to develop a set of rules (protocols) that govern how cellular subscribers units (mobile phone) communicate with the cellular systems base-stations and switching subsystem [3]. They work on the following 
basic cellular concepts: frequency and channel assignments, radio modulation types, maximum power levels, messaging protocols, and call processing sequences.

Analogue systems used frequency division multiple access (FDMA) to communicate, which means, every call uses a channel (frequency) for voice communication.
It has small traffic capacities, and the use of radio spectrum is profuse [4]. Examples of analog systems are Advance Mobile Phone Service (AMPS), Total Access Communication System (TACS), Nordic Mobile Telephony (NMT), Japanese TACS (JTACS), and Csystem and so on. The Table I summarizes the configurations details of some analog systems.

TABLE I. ANALOG SYSTEMS SUMMARY (SOURCE: [5])

\begin{tabular}{|c|c|c|c|c|}
\hline System & $\begin{array}{ll}\text { Frequency } & \text { range } \\
(\mathrm{MHz}) & \end{array}$ & $\begin{array}{ll}\begin{array}{l}\text { Channel Spacing } \\
(\mathrm{KHz})\end{array} & \\
\end{array}$ & Number of Channel & Region \\
\hline AMPS & $824-849 / 869-894$ & 30 & 832 & $\begin{array}{l}\text { The Americas, Australia, } \\
\text { China, South-East Asia }\end{array}$ \\
\hline NMT-450 & $453-457.5 / 463-467.5$ & 25 & 180 & Europe \\
\hline NMT-900 & $890-915 / 463-467.5$ & $12.5 *$ & 1,999 & $\begin{array}{l}\text { Europe, China, India, } \\
\text { Africa }\end{array}$ \\
\hline TACS & $890-915 / 935-960$ & 25 & 1000 & United Kingdom \\
\hline ETACS & $872-905 / 917 / 950$ & 25 & 1,240 & Europe, Africa \\
\hline $\mathrm{C}-450$ & $\begin{array}{l}450-455.74 / \quad 460- \\
465.74\end{array}$ & $10 *$ & 573 & Germany Portugal \\
\hline RTMS & $\begin{array}{l}450-455 / \\
460-465\end{array}$ & 25 & 200 & Italy \\
\hline $\begin{array}{l}\text { RadioCom- } \\
2000\end{array}$ & $\begin{array}{lr}165.2-168.4 / 169.8-173 \\
192.5-199.5 / & 200.5- \\
207.5 & \\
215.5-233.5 / & 207 . \\
215.5 & \\
414.8-418 / & \\
424.8-428 & \end{array}$ & 12.5 & $\begin{array}{l}256 \\
560 \\
640 \\
256\end{array}$ & France \\
\hline JTACS/NTACS & $\begin{array}{l}915-925 / \\
860-870 \\
898-901 / \\
843-846 \\
918.5-922 / 863.5-867\end{array}$ & $\begin{array}{l}25 / 12.5^{*} \\
25 / 12.5^{*} \\
12.5^{*}\end{array}$ & $\begin{array}{l}400 / 800 \\
120 / 240 \\
280\end{array}$ & Japan \\
\hline
\end{tabular}

Frequency interleaving using overlapping or interstitial channels; the channel spacing is half the nominal channel bandwidth.

The limitation of analog became clear as the subscribers increased since a subscriber will occupy a channel in the analog systems. Digital systems came into existence to handle the limitation in the analog systems. The general characteristics of Time Division Multiple Access (TDMA), Global System for Mobile Communications (GSM), and Code Division Multiple Access (CDMA) promise to increase the efficiency of cellular telephone systems to allow a greater number of simultaneous conversations.

\section{III. $\quad 2 \mathrm{G}$ and $2.5 \mathrm{G}$ SYSTEMS NETWORK}

\section{A. Global System for Mobile Communications (GSM)}

The Global System for Mobile communications is a digital cellular communication system. GSM was developed in order to create a common European mobile telephone standard but it has been rapidly accepted worldwide. From 1982 to 1985 discussions were held to decide between building an analog or digital system. After multiple field tests, a digital system was adopted for GSM. The next task was to decide between a narrow or broadband solution. In May 1987, the narrowband time division multiple access and frequency division multiple access (TDMA/FDMA) solution was chosen [2]

GSM is a major digital cellular radio network in Europe since 1980s, where it is used in the $900 \mathrm{MHz}$ radio band. The radio band is also known as frequency of the network [6]. GSM has been standardized to $900 \mathrm{MHz}, 1800 \mathrm{MHz}$, and $1900 \mathrm{MHz}$. The $900 \mathrm{MHz}$ and $1800 \mathrm{MHz}$ used the same base band signals, but they operate on different carrier frequencies. The radio frequency separation between matching the uplink and downlink carrier for $900 \mathrm{MHz}$ is $45 \mathrm{MHz}$ while that of $1800 \mathrm{MHz}$ is $90 \mathrm{MHz}$. The $1900 \mathrm{MHz}$ is used mainly in North America. The frequency separation between matching the Uplink and downlink frequencies is $80 \mathrm{MHz}$.

Other GSM Specifications are: 
- Channel separation - the separation between adjacent carrier frequencies in GSM is $200 \mathrm{kHz}$.

- Modulation-Modulation is the process of sending a signal by changing the characteristics of a carrier frequency. This is done in GSM via Gaussian minimum shift keying (GMSK).

- Transmission rate-GSM is a digital system with an over-the-air bit rate of $270 \mathrm{kbps}$.

\section{B. GSM Network Interfaces}

The GSM network is made up of geographic areas. As shown in Fig. 3, these areas include Cells, Location Areas (LAs), MSC/VLR service areas, and Public Land Mobile Network (PLMN) areas. The cell is the area given radio coverage by one base transceiver station. The GSM network identifies each cell via the Cell Global Identity (CGI) number assigned to each cell. The Location Area (LA) is a group of cells and subscribers are paged in the area. One or more base station controllers serve each LA, but with a single MSC (see Fig. 1). Each LA is assigned a Location Area Identity (LAI) number.

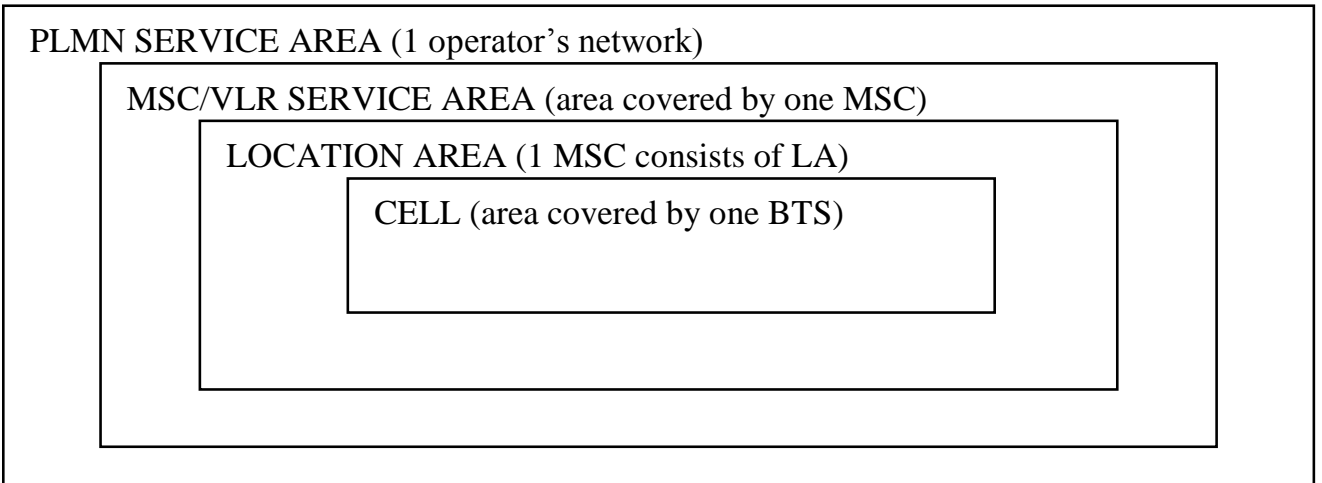

Figure 1. PLMN Service Area (Courtesy: [2])

An MSC/VLR service area represents the part of the GSM network that is covered by one MSC and which is reachable, as it is registered in the VLR of the MSC. The PLMN Network area is an area served by one network operator

\section{The GSM Network Entities}

The GSM network is divided into three major systems: the base station Subsystem (BSS), the switching Subsystem (SS), and the operation and support system (OSS). The basic GSM network elements are shown in Fig. 2, details of all these subsystems are described in subsequent sections. Figure 2. GSM Network Elements (Source: [2])

\section{Mobile Station}

The Mobile station consists of Mobile equipment (mobile phone) and Subscriber identity module (SIM). SIM provides personal mobility so that the user can have access to subscribed services irrespective of a specific terminal [2]. SIM has a microprocessor and a memory that can hold information that will remain in the chip even if the SIM card is deactivated [7]. SIM is stored inside the mobile phone to identify each subscriber on the GSM Network. SIM card contains International Mobile Subscriber Identity (IMSI) this is used to identify the subscriber to the system, a secret key for authentication and other information. The SIM card has a Personal information Number, which is used by the subscriber to restrict access to the SIM card.

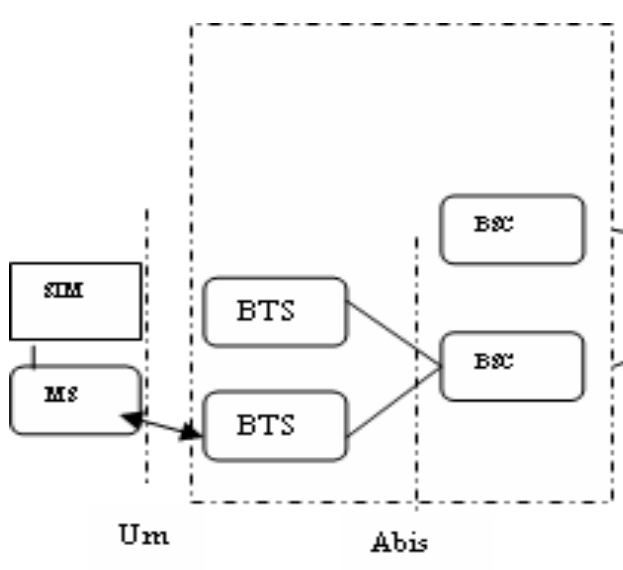

Base Station Subsystem

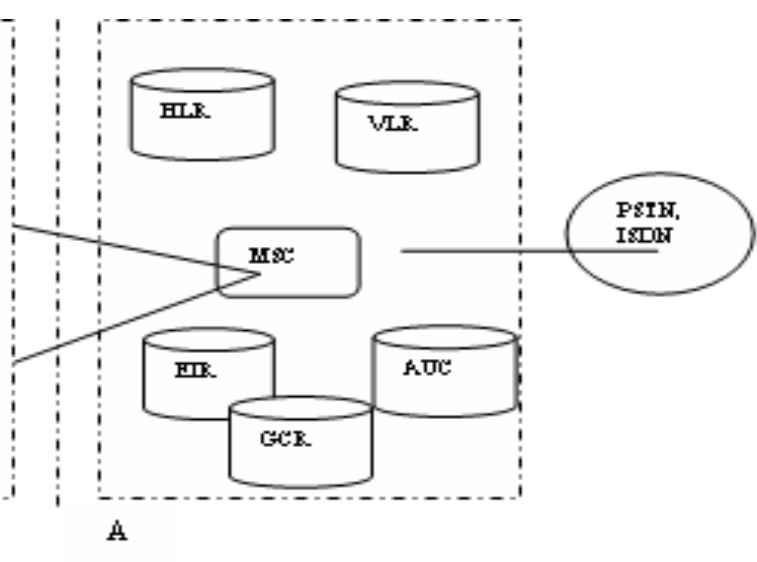

Network Subsystem

Figure 2. GSM Network Elements (Source: [2]) 


\section{E. The Base Station System (BSS)}

A GSM network is comprised of many base station subsystems (BSSs), and it consists of base station controllers (BSCs) and the base transceiver stations (BTSs). The BSS performs the necessary functions for monitoring radio connections to the Mobile Station (MS), coding and decoding voice, and rate adaptation to and from the wireless network. The covered area of a cellular network is divided into smaller areas called cells. Each cell is connected to a base station system, which communicates simultaneously with all mobiles within thecell, and passes traffic to the Mobile Switching Center. The Base Station System is connected to the mobile phone via a radio interface [8].

\section{F. The Switching System}

The central component of the Network switching subsystem (SS) is the Mobile services Switching center (MSC). MSC is the link between the Base station subsystem and network switching subsystem of the GSM Network Also it acts as the link between the cellular system and the PSTN. MSC is responsible for performing call routing to a roaming subscriber, registration, authentication, location updating, handovers and subscriber-related functions [1]. These services are provided in conjunction with several functional database entities, which together form the Network switching system. The databases are HLR, VLR, AUC, EIR, GCR, MXE, MSN, and SMSC. Signaling between functional units in the MSC uses Signaling System Number 7 (SS7). SS7 is widely used for trunk signaling in the ISDN and in public networks. Signaling allows different functional units to interwork successfully and provide a data communication path between network nodes [9].

GSM subscribers could be anywhere within the network when they make a call, the MSC must ensure that the calls are routed to the appropriate destination. In other to simplify this network management function, the entire PLMN network is divided into service areas and each service area is allotted one MSC to monitor the activities. MSC are interconnected to monitor the movement of subscribers.

Some MSCs are called gateway MSC (GMSC). A gateway is a node used to interconnect two networks. The GMSC is the interface between mobile network and other mobile network or any other network. All incoming calls to the PLMN from another PLMNs, fixed wireless or landlines must pass through the gateway [10]. Gateway MSC works as an incoming transit exchange for the GSM/PLMN. Gateway MSC contains interconnecting functions to make interconnections between two PLMNs, PSTN or fixed wireless (see Fig. 2). They also route incoming calls to the proper MSC within the Network. In summary, the role of MSC is to manage the communications between the GSM users and other telecommunication users.

\section{G. Applications on GSM}

There are two basic types of services offered through GSM: telephony and data. Telephony services are mainly voice services that provide subscribers with the complete capability to communicate with other subscribers [11]. Data services provide the capacity necessary to transmit appropriate data signals between two access points creating an interface to the network. In addition to basic services, the following subscriber services are supported by GSM: Dual-tone Multifrequency (DTMF), Short Message Services, Cell broadcast, Voice mail, Fax mail, Call forwarding, Barring of outgoing calls, Barring of incoming calls, Advice of charge (AoC), Call Waiting.

\section{H. General Packet Radio System (GPRS)}

The general packet radio system (GPRS) provides packet radio access for mobile Global System for Mobile Communications (GSM). GPRS is built on GSM network to provide effective data service like internet applications. It allows data to be sent and received across the mobile circuit switched network. The introduction of packet-switching service to circuit-switching network has neccesitated the upgrades of some hardware and software equipments at the GSM network [12]. GPRS is the first step toward an end-to-end wireless infrastructure. The main importance of GPRS is to allow circuitswitched GSM subscribers have access to data services since the transmission speed increased up to $172 \mathrm{kbps}$ which is not achievable under GSM/SMS.

Packet switching means that GPRS radio resources are used only when users are actually sending and receiving data. Rather than dedicating a channel to a mobile data user for a fixed period, the available radio channel can be shared between several users [12]. In addition, a mobile host can be allocated more than one of the eight (8) available slots in the TDMA Frame. GPRS improves the peak time capacity of GSM supporting virtual connectivity and migrating traffic that was previously sent using Circuit Switched Data to GPRS and reduces SMS center and signaling channel loading

Two extensions were made to GSM Switching system to accommodate the GPRS packet switching, they are; Gateway GPRS support node (GGSN) and Serving GPRS support node(SGSN). GGSN performs functions equivalent to gateway MSC and SGSN performs functions comparable to Visited MSC (VMSC/VLR) [13]. The BSC includes the packet control unit (PCU), which supports all relevant GPRS protocols for communication over the air interface $(\mathrm{Gb})$ in Fig. 3.

GPRS defines four channels coding schemes namely $\mathrm{CS} 1, \mathrm{CS} 2, \mathrm{CS} 3$ and $\mathrm{CS} 4$ with radio data rates $8.8 \mathrm{kbps}$, $13.3 \mathrm{kbps}, 15.6 \mathrm{kbps}$ and $21.4 \mathrm{kbps}$ per slots in the 8TDMA frame respectively as shown in Table II. In practice, CS3 is commonly used for providing 124.8 kbps per frequency channel in TDMA frame, but in the real life experience only about $40 \mathrm{~kb} / \mathrm{s}$ are normally used maximally because no operator will allow a full frequency for GPRS user. 


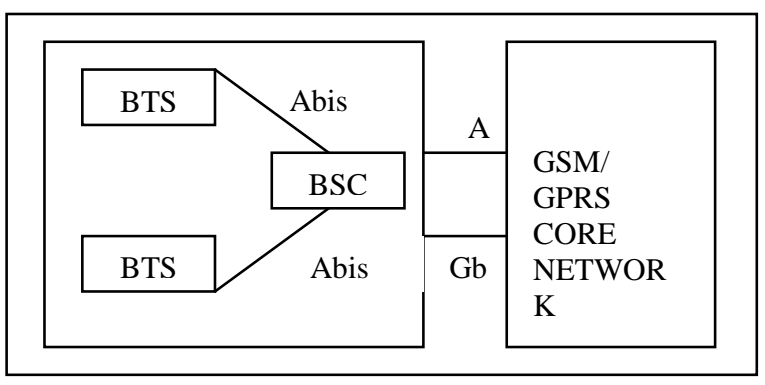

Figure 3. GSM/GPRS Evolution (source: [14])

TABLE II. GPRS CODING (SOURCE: [15], [16])

\begin{tabular}{|l|l|l|l|l|}
\hline $\begin{array}{l}\text { GPRS Coding } \\
\text { Scheme }\end{array}$ & CS-1 & CS-2 & CS-3 & CS-4 \\
\hline $\begin{array}{l}\text { RLC block } \\
\text { radio (bytes) }\end{array}$ & 23 & 33 & 39 & 53 \\
\hline Data rate & 9.05 & 13.4 & 15.6 & 21.4 \\
\hline
\end{tabular}

Moreover, this capacity level is still acceptable for internet access and web browsing. GPRS facilitates instant connections whereby information can be sent or received immediately as the need arises without any modem dial-up connection. GPRS can only be enjoyed by subscribers with mobile phone that is GPRS enabled and subscribe to GSM network that has been GPRS upgraded.

However, GPRS has some limitations both in the speed and service capacities. GPRS has limited capacity because it depends on the GSM timeslots to operate, thus, limit the capacity expansion of GPRS. Theoretically, the maximum GPRS data transmission speed of $172.2 \mathrm{kbps}$ would require a single user taking up the 8 timeslots without any error protection. Nevertheless, it is unlikely that a network operator will allow all timeslots to be used by a single user. Also, the store and forward engine present in the short message center of GSM service is absent in the GPRS standard thereby making SMS to solely rely on GSM. GPRS packets are sent on all different directions to reach the same destination. As a result there is possibility of some of the packets to get lost or corrupted on the way. Though GPRS standard recognize this and then incorporates data integrity and retransmission strategies, however, the result is that potential transit delays can occur.

\section{Enhanced Data Rates for Global Evolution (EDGE)}

Enhanced Data Rates for GSM Evolution (EDGE) is a standardized set of improvements to the GSM/GPRS network radio interface and brings higher data rates. EDGE allows consumers to connect to the Internet and send/receive data, at up to three times faster than possible with an ordinary GSM/GPRS network. EDGE builds on the GSM infrastructure uses the same channel structure, frequency planning, protocols and coverage as depicted in Fig 4. EDGE is another step in GSM/GPRS evolution towards $3 \mathrm{G}$.

The EDGE network offers average data speeds of up to $384 \mathrm{kbps}$ and it is faster than any other wireless data network including CDMA and GPRS [17]. GPRS and GSM are based on a modulation technique known as Gaussian minimum-shift keying (GMSK) but EDGE is based on a new modulation scheme that allows a much higher bit rate across the air interface- this is called eight-phase-shift keying (8-PSK) modulation [12]. This technique uses the same GSM carrier bandwidth and timeslot structure and shares the GPRS network elements as make out in Fig. 4. Enabling this application requires some hardware changes as well as adaptations in the signaling structure on the BSS side [14]. Nine modulation and coding schemes are defined for edge; MC-1 to MC-9 as stated in Table III. Charges on EDGE networks are done as per amount of data transfer at a given time, so, subscribers pay for data sent and received and not on the number of minutes spent when connected to the Internet.

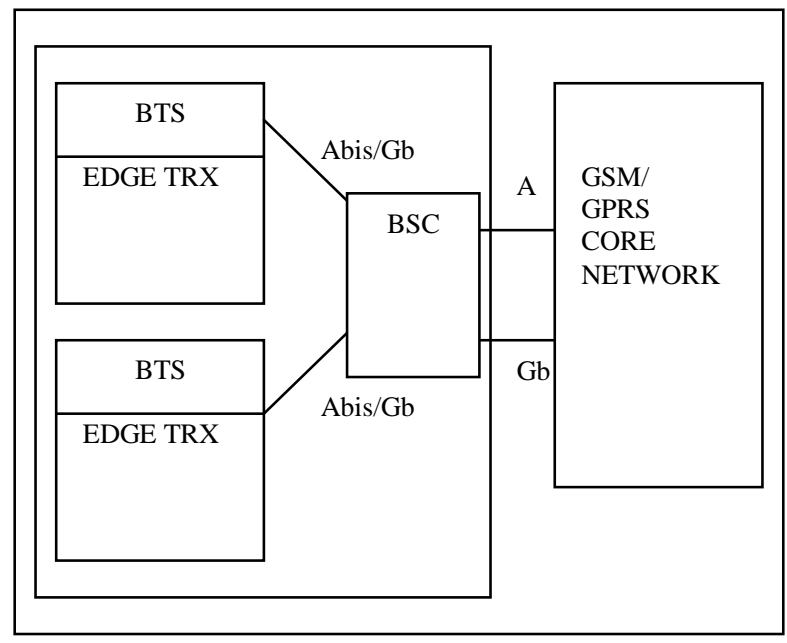

Figure. 4. EDGE enhancement for GSM/GPRS Network (source: [14])

It is very essential that the subscriber be equipped with the right mobile equipment for them to enjoy the service. Some new mobile phone handsets and Personal Digital Assistants (PDAs) come with EDGE-capability and thereby allow instant connection to internet. Another alternative is to connect an EDGE-enabled handset to a Personal Computer, laptops through edge-capable PC cards [13].

TABLE III. EDGE CODING (SOURCE [16])

\begin{tabular}{|l|l|l|l|l|l|l|l|l|l|}
\hline GPRS Coding Scheme & MC-1 & MC-2 & MC-3 & MC- 4 & MC-5 & MC-6 & MC-7 & MC-8 & MC- 9 \\
\hline $\begin{array}{l}\text { RLC radio block } \\
\text { (bytes) }\end{array}$ & 22 & 28 & 37 & 44 & 56 & 74 & 112 & 136 & 148 \\
\hline
\end{tabular}




\section{THIRD GENERATION (3G) WIRELESS SYSTEMS}

International mobile telecommunication (IMT)-2000 is the standard choosing for $3 \mathrm{G}$ communications system development. IMT-2000 is a set of requirements defined by International telecommunication union in the year 2000, thus, the name IMT-2000. IMT-2000 aims to realize $144 \mathrm{Kbps}, 384 \mathrm{Kbps}$, and $2 \mathrm{Mbps}$ under high mobility, low mobility, and stationary environments respectively as shown in Table IV. 3G communications system have the ability to provide high data transmission capability for processing multimedia applications, internet personal services, the convergence of digitization, mobility based on the global standard [5]. The $2 \mathrm{G}$ wireless communications was driven by the high demand of voice communication and that was successful, but there is limitation to data it can transmit. Now, there is a paradigm shift to high demand for high-speed data transmission, which forms the basis for $3 \mathrm{G}$. In all the $3 \mathrm{G}$ systems, there is a backward compatibility with the $2 \mathrm{G}$ systems for voice communications.

The international bodies responsible for the standardization of $3 \mathrm{G}$ wireless systems are the $3 \mathrm{GPP}$ and 3GPP2. The 3GPP based its evolution to all-IP core network on GSM/GPRS while 3GPP2 is based on CDMA1xRTT. Mobility management of 3GPP is based on GSM/UMTS Packet Switched network and 3GPP2 is based on the Mobile IP (RFC2002) [5]. 3GPP was established to harmonize standards that will evolve GSM/GPRS to WCDMA $3 \mathrm{G}$ and 3GPP2 for CDMA fixed wireless to CDMA2000 3G [18]. The Table II below shows the characteristics of the two $3 \mathrm{G}$ systems. IMT-2000 adopted a CDMA-based system that brought about the capability of offering worldwide roaming by fixing the code transmission rate (chip rate).

Deployments to $3 \mathrm{G}$ have different paths for the operators to take. Some have adopted moving through the $2.5 \mathrm{G}$ to $3 \mathrm{G}$ that is, moving through GPRS $(171 \mathrm{Kbps})$ to $3 \mathrm{G}$ as the core network of GSM/GPRS can be extended to support the $3 \mathrm{G}$. The most modifications have to be done at the base station subsystem and at the mobile station to be able to suit the new application.

The TDMA and some GSM operators are planning for Edge (384 Kbps) before moving to $3 \mathrm{G}$ while the CDMA fixed wireless operators are going for CDMA single carrier radio transmission technology (CDMA1xRTT, $144 \mathrm{Kbps}$ ) as a step towards the 3G. Wideband CDMA (WCDMA, 2Mbps) is a standard for GSM evolution to $3 \mathrm{G}$ while CDMA2000 as the successor for CDMA fixed wireless according to IMT 2000 requirements. Furthermore, operators can deploy an independent 3G Core Network from the $2 \mathrm{G}$ Core Network, but interoperability tests (IOTs) will be needed depending on the architecture because it is likely possible that there is going to be multivendor scenario of the equipments to be used [5].
TABLE IV. WCDMA AND CDMA2000 SUMMARIES (SOURCE [5])

\begin{tabular}{|c|c|c|}
\hline & WCDMA & CDMA2000 \\
\hline Frequency & 2-GHz Band & - \\
\hline Bandwidth & $\begin{array}{l}\text { 1.25/5/10/20-MHz } \\
\text { (DSCDMA) }\end{array}$ & $\begin{array}{l}1.25 / 5 / 10 / 20- \\
\mathrm{MHz}(\mathrm{DSCDMA}) \\
3.75 / 5- \\
\mathrm{MHz}(\mathrm{MCCDMA})\end{array}$ \\
\hline Chip rate & $\begin{array}{l}\text { 3.84Mcps } \\
\text { (DSCDMA-FDD, } \\
\text { DSCDMA-TDD) }\end{array}$ & $\begin{array}{l}\text { 3.84 Mcps } \\
\text { (DSCDMA-FDD) } \\
\text { 3.6864 Mcps } \\
\text { (MCCMA-FDD) }\end{array}$ \\
\hline Data Rate & $\begin{array}{l}144 \text { kbps (high- } \\
\text { mobility } \\
\text { environment) } \\
384 \text { kbps(low- } \\
\text { mobility } \\
\text { environment) } \\
2 \text { Mbps (stationary } \\
\text { environment) }\end{array}$ & - \\
\hline $\begin{array}{l}\text { Synchroniz } \\
\text { ation } \\
\text { between } \\
\text { base station }\end{array}$ & $\begin{array}{l}\text { Asynchronous/Syn } \\
\text { chronous }\end{array}$ & Synchronous \\
\hline Exchange & GSM-MAP based & ANSI-41 based \\
\hline
\end{tabular}

\section{3.5G SYSTEMS NETWORK}

\section{A. High-Speed Packet Access (HSPA)}

This is a collection of $3 \mathrm{G}$ mobile telephony protocols that extend and improve the performance of existing UMTS protocols. This provides a roadmap for UMTSbased networks to increase their data transfer speeds and capacity. Two standards High-Speed Downlink Packet Access (HSDPA) and High-Speed Uplink Packet Access (HSUPA) have been established and a further standard High Speed OFDM Packet Access (HSOPA) is being proposed [19].

\section{B. High-Speed Downlink Packet Access (HSDPA)}

HSDPA is a $3 G$ mobile telephony protocol in the HSPA family. In order to meet the increasing demand for high data-rate multimedia services, the $3 \mathrm{rd}$ Generation Partnership Project (3GPP) released a new high-speed data transfer feature named High-Speed Downlink Packet Access (HSDPA). HSDPA provides impressive enhancements over WCDMA R'99 for the downlink. Current HSDPA deployments now support $1.8 \mathrm{Mbit} / \mathrm{s}, 3.6 \mathrm{Mbit} / \mathrm{s}, 7.2 \mathrm{Mbit} / \mathrm{s}$ and $14.4 \mathrm{Mbit} / \mathrm{s}$ in downlink data applications, with shorter connection and response times [19]. HSDPA high data rates improve the use of streaming applications like picture/video messaging and location-based services, while lower roundtrip delays will benefit Web browsing applications [20]. 


\section{High-Speed Uplink Packet Access (HSUPA}

This is the second $3 \mathrm{G}$ mobile telephony protocol in the HSPA family with the up-link speeds up to 5.76 Mbit/s. The technical purpose of the HSUPA is to improve the performance of uplink dedicated transport channels [19]. The 3GPP is working beyond HSUPA to further advancing transfer rates. The next protocol called HSOPA will provide up to $100 \mathrm{Mbit} / \mathrm{s}$ for downlink and $50 \mathrm{Mbit} / \mathrm{s}$ for uplink.

\section{FOURTH-GENERATION WIRELESS SYSTEM} (4G)

Fourth-Generation wireless System (4G) is a concept of heterogeneous networks, including a large number of access networks, with the IP protocol stack as a common denominator, providing connectivity for all the users at any place and at any time [5]. 4G allows the integration of available heterogeneous and homogeneous networks into a single platform capable of supporting user roaming between them while not interrupting active communications [21].

The $4 \mathrm{G}$ is driven by low cost, high-speed data, application ubiquity, high degree of personalization and synchronization between various user appliances [22]. Unlike $3 \mathrm{G}$, which is based on two parallel infrastructures consisting of circuit switched and packet switched network nodes respectively, $4 \mathrm{G}$ is based on packet switching only [23]. It consists of end-to-end IP solution with better quality data, video and sound services due to high bandwidth, and convergence of networks services (enterprise, fixed and cellular). The design target for radio performance is to achieve a scalable capacity from 50 to $500 \mathrm{bit} / \mathrm{s} / \mathrm{Hz} / \mathrm{Km}^{2}$ compared to the $3 \mathrm{G}$ best performance of $10 \mathrm{bit} / \mathrm{s} / \mathrm{Hz} / \mathrm{Km}^{2}$ using High speed downlink packet access (HSDPA) and other $3 \mathrm{G}$ technology.

The $4 \mathrm{G}$ working group has defined the following as objectives of the $4 \mathrm{G}$ wireless communication standard [23]:

- A spectrally efficient system (in bits $/ \mathrm{s} / \mathrm{Hz}$ and $\mathrm{bit} / \mathrm{s} / \mathrm{Hz} / \mathrm{site})$

- High network capacity: more simultaneous users per cell

- A nominal data rate of $100 \mathrm{Mbit} / \mathrm{s}$ while the client physically moves at high speeds relative to the station, and $1 \mathrm{Gbit} / \mathrm{s}$ while client and station are in relatively fixed positions as defined by the ITU-R

- A data rate of at least $100 \mathrm{Mbit} / \mathrm{s}$ between any two points in the world

- Smooth handoff across heterogeneous networks

- Seamless connectivity and global roaming across multiple networks

- High quality of service for next generation multimedia support (real time audio, high speed data, HDTV video content, mobile TV, etc)
- Interoperability with existing wireless standards, and

- An all IP, packet switched network.

A new access schemes like OFDMA, Single Carrier FDMA, and MC-CDMA have been proposed as part of the upcoming $4 \mathrm{G}$ standards because the present TDMA suffers from inherent inefficiencies due to the need for guard periods between frames and CDMA have poor flexibility and scalability.

\section{EVOLUTION SCENARIO TO 4G}

\section{A. Wireless Local Area Networking (WLAN) and Universal Mobile Telecommunication System UMTS Interoperability}

Until now, 802 standards do not support handover between different types of networks (vertical handover), but only supports handover within the same network type (horizontal handover); this new standard will now allow the vertical handovers [24]. Mobile IP (MIP) provides handover mechanisms for handover across subnets of different types of networks. Roaming of mobile users between WLAN hotspots or between GPRS/UMTS cells can be achieved with the help of the Mobile Internet Protocol (MIP). As an evolutionary step towards the $4 \mathrm{G}$ mobile communications, mobility in heterogeneous IP networks with both UMTS and IEEE 802.11 WLAN systems is seen as one of the central issues in making the $4 \mathrm{G}$ of telecommunication networks and systems [5].

WLAN is based on the 802.11a and 802.11b standards to offer bandwidth up to 11 megabits per second (Mbit/s) or $54 \mathrm{Mbit} / \mathrm{s}$ at relatively low deployment costs, but restrict the movement rate of the user to 5Mbit/s [21]. There is no technology or service can provide ubiquitous coverage, therefore, it will be necessary for a mobile terminal to employ various points of attachment to maintain connectivity to the network at all times. The most attractive solution for such consideration is to utilize high-bandwidth data networks such as IEEE $802.11 \mathrm{a} / \mathrm{b}$ WLAN whenever they are available and switch to an overlay public network such as UMTS with lower bandwidth when there is no WLAN coverage. A cellular phone user in the midst of a call should be able to enter a wireless local area networks (WLAN) 802.11 network hotspot and be seamlessly handed off from a UMTS network to the 802.11 network and back again when leaving the hotspot.

\section{B. WLAN and Long Term Evolution}

The UMTS systems proposed upgrade path to $4 \mathrm{G}$ is the 3GPP Long Term Evolution effort through High Speed OFDM Packet Access (HSOPA). HSOPA will succeed HSDPA and HSUPA technologies if adopted. HSOPA has Flexible bandwidth usage with $1.25 \mathrm{MHz}$ to $20 \mathrm{MHz}$ bandwidths, Increased spectral efficiency at 2-4 times more than in $3 \mathrm{GPP}$ release 6 , peak transfer rates of 
$100 \mathrm{Mbps}$ for downlink and $50 \mathrm{Mbps}$ for uplink [25]. HSOPA uses Orthogonal Frequency Division Multiplexing (OFDM) and multiple-input multipleoutput (MIMO) antenna technology to support up to 10 times as many users as W-CDMA based systems, with lower processing power required on each handset [26]. The improvements in performance will allow wireless operators to offer voice, high-speed interactive applications including large data transfer and featurerich services like IPTV with full mobility.

\section{3GPP2 Movement}

The 3GPP2 evolution to $4 \mathrm{G}$ from 3G CDMA2000 is Ultra Mobile Broadband (UMB). This is under development. The UMB will have up to $280 \mathrm{Mbps}$ peak data rate. It will put these access mechanisms - CDMA, TDM, OFDM and OFDMA into a single air interface through its feature called multiple radio and advanced antenna techniques (Multiple Input Multiple output (MIMO)) [27]. This feature brings about improved interference management techniques thereby brings improved voice and data services.

\section{The Worldwide Interoperability for Microwave Access (Wimax)}

WIMAX is a technology aimed at providing wireless data over long distances in a variety of ways, from point-to-point links to full mobile cellular type access. It is based on the interoperable implementations of IEEE 802.16 wireless networks standard. The name WIMAX was created by the WiMAX Forum, which was formed in June 2001 to promote conformance and interoperability of the standard [28]. WIMAX provides pure packet switched services with no need to support the circuit switching services required for voice systems.

The original WIMAX standard (IEEE 802.16) specified 10 to $66 \mathrm{GHz}$ range. It was updated in 2004 to 802.16-2004 (802.16d), added specifications for the 2 to $11 \mathrm{GHz}$ range. 802.16-2004 was updated to 802.16-2005 (802.16e) in 2005 and uses scalable orthogonal frequency-division multiple access (SOFDMA) as opposed to the OFDM version with 256 subs- carriers in 802.16d. [29]. More advanced versions including 802.16e also bring Multiple Antenna Support through Multiple-input multiple-output (MIMO) communications. As a result, it offers benefits in terms of coverage, self installation, power consumption, frequency re-use bandwidth efficiency and capability for full mobility support. Mobile WIMAX based upon 802.16e-2005 has been accepted as IP-OFDMA for inclusion as the sixth wireless link system under IMT2000

The bandwidth of WiMAX makes it suitable for the following potential applications [29]:

- Connecting Wi-Fi hotspots with each other and to other parts of the Internet.

- Providing a wireless alternative to cable and DSL for last mile (last $\mathrm{km}$ ) broadband access.
- Providing high-speed data and telecommunications services at about $70 \mathrm{Mbps}$.

- Providing a diverse source of Internet connectivity as part of a business continuity plan. That is, if a business has a fixed and a wireless Internet connection, especially from unrelated providers, they are unlikely to be affected by the same service outage.

- $\quad$ Providing nomadic connectivity.

The interoperability requirements between the $\mathrm{Wi}-\mathrm{Fi}$ and WIMAX as well as the dual mode cells introduced into high capacity network centers in licensed and unlicensed bands will go a long way to bring answers to accessing internet contents anywhere and everywhere.

\section{CONCLUSION}

Mobile Communication is the tool that had tremendously impacted on the communication technology in this era and promised to be the tool that will unite the world. The last has not been heard as the height to which this technology is taken us has not been imagined. Therefore, is necessary to know how we got to this point so as to acknowledge that we had just begun. This paper has no doubt opened our eyes to this mobile communication technology.

\section{REFERENCES}

[1] http://www.iec.org“: Cellular Communication”.

[2] Scourias J. (1999) "Overview of the Global System for Mobile Communication". www.iec.org/online/tutorial.

[3] Kuboye B.M., (2006). "Development of A Framework for Managing Congestion in Global System for Mobile Communications in Nigeria", M.Tech Thesis.

[4] Mobile Communication www.epanorama.net/links/tele_mobile.html.

[5] Prasad and Muñoz, (2003) "WLAN and WPAN Towards 4G wireless", Norwood, MA: Artech House.

[6] Kuboye B. M., Alese B. K., Fajuyigbe O., Adewale O. S. (2011). "Development of Models for Managing Network Congestion on Global System for Mobile Communication (GSM) in Nigeria", Journal of Wireless Networking and Communications 2011; 1(1): 8-15. Available online http://journal.sapub.org/jwnc, DOI:10.5923/j.jwnc.20110101.02.

[7] Hartel, Levine R. Livingtone G. (1999), “GSM Superphones", McGraw-Hill.

[8] Perianan R. and Fahham F. J. (1996) "Performance Issues of Cellular Networks" www.dsc.doc.ic.uk/Surprise--96/Journal.

[9] Ericsson, (2002) "GSM Raw Capacity Solution" Ericsson Review no 2. 
[10] Mehrotra A. (1997) "GSM System Engineering", Norwood, MA: Artech home, Inc.

[11] Déchaux and Scheller, (1993). "What are GSM and DCS" Electrical Communication Journal, $2^{\text {nd }}$ Quarter.

[12] Pentikousis (2003) "Wireless Data Networks"; The Internet Protocol Journal, Vol. 8 number 1.

[13] Kuboye, B.M. and B.K. Alese. (2009). "The Pathway of GSM to $3 \mathrm{G}$ Systems in Nigeria". Pacific Journal of Science and Technology. $10(2): 388-397$.

[14] www.kate-kom.com.

[15] Dahmouni H., Morin B. and Vaton S., (2005) "Performance Modeling of GSM/GPRS Cells with Different Radio Resource Allocation Strategies", Methods and Tools for Traffic Engineering, France Telecom R \& D, Belfort, France..

[16] Budura G., Balint C., Budura A., and Marza E., (2009), "Traffic Models and Associated Parameters in GSM/ (E) GPRS Networks, WSEAS Transactions on Communications", Issue 8, Volume.

[17] Cingular wireless (2005) "Cingular wireless business solutions" Cingular technical review.

[18] www.iec.org: UMTS Protocol and Testing.

[19] en.wikipedia.org/wiki/3GPP_long_term_evolution

[20] Qualcomm CDMA Technologies, Oct 2004; "HSDPA for Improved Downlink Data Transfer"
en.wikipedia.org/wiki/3G.

[21] Fikouras and Aust, (2003). "Migration Issues to $2.5 \mathrm{G}$ and $3 \mathrm{G}$ for Internet Protocol-based Technologies", Wireless Technology Business Briefing.

[22] Rouffet et al (2005) " $4 \mathrm{G}$ Mobile" Alcatel Telecommunications Review, 2nd Quarter www.alcatel.com/atr.

[23] en.wikipedia.org/wiki/4G.

[24] en.wikipedia.org/wiki/ieee-802.21.

[25] en.wikipedia.org/wiki/hsopa.

[26] www.nortel.com/corporate/news.

[27] zxwww.quiantagroup.com.

[28] www.wimaxforum.org/technology.

[29] en.wikipedia.org/wiki/wimax.

B. M. Kuboye, born in 1971, holds a Ph.D in Computer Science and presently lectures at the Federal University of Technology, Akure from Nigeria. He is member of the Nigeria Computer Society and has published in both local and International journals. His main research interests include Computer and Wireless Networks Communication and Geographical Information System.

How to cite this paper: Kuboye Bamidele Moses,"Mobile Communication Evolution", IJMECS, vol.6, no.1, pp.25-33, 2014.DOI: $10.5815 /$ ijmecs.2014.01.03 